\title{
Desnudando um corpo perturbador: a "bipedia compulsória" e o fetiche pela deficiência na Dança
}

\author{
Desnudar un cuerpo perturbador: \\ "Bipedia obligatoria" y fetiche por \\ la deficiencia de baile
}

Carlos Eduardo Oliveira do Carmo ${ }^{1}$

https://orcid.org/0000-0003-3483-2684

Resumo: Este artigo apresenta a "bipedia compulsória", conceito em desenvolvimento pelo autor, como uma estrutura social, política, econômica e cultural que determina padrões excludentes pautados na normatividade do corpo, subjugando e inferiorizando as potencialidades da pessoa com deficiência, tomadas por incapazes e inaptas. Estabelece diálogos com autores da Teoria Crip, que compreende a deficiência em seus aspectos históricos e culturais, em contraposição ao modelo social. Observa o fenômeno da "bipedia compulsória" pelo viés da Dança, trazendo uma análise dos espetáculos "Striptease-Bicho" e "O Corpo Perturbador", que abordam o devoteísmo - fetiche pela deficiência - associando-o a determinados comportamentos hierárquicos recorrentes na Dança e nas relações sociais estabelecidas com as pessoas com deficiência. Entende tais relações pautadas pelo pensamento abissal (SANTOS, 2010), que determina diferenciações entre corpos aptos ou não para dançar.

Palavras-chave: Bipedia compulsória; Deficiência; Dança.

Resumen: Este artículo presenta la bipedia obligatória, campo conceptual en desarrollo por el autor, como una estructura social, política, economica y cultural que determina patrones excluyentes

\footnotetext{
1 Doutorado Multiinstitucional e Multidisciplinar em Difusão do Conhecimento. E-mail: eduimpro@gmail.com
} 
pautados en la normatividad del cuerpo, socavando y bajando las potencialidades de la persona con deficiencia, consideradas incapazes y no aptas. Establece diálogos con autores de la Teoria Crip que entiende la deficiencia en sus aspectos históricos y culturales, en contraposición al modelo social. Observa el fenomeno de la Bipedia Obligatória por la mirada de la Danza, trayendo un análise de los espectáculos Striptease-Bicho y O Corpo Perturbador que abordan la devoción - fetiche por la deficiencia - asociándolo a determinados comportamientos hierárquicos frequentes en la Dança y en las relaciones sociales establecidas con las personas con deficiencia. Entiende tales relaciones pautadas por el pensamiento abissal (SANTOS, 2010) que determina diferenciaciones entre cuerpos aptos o no para danzar.

Palabras clave: Bipedia obligatória; Deficiencia; Danza.

No escuro do teatro, uma voz grita na caixa de som: "Eis que chegam Eles...". ${ }^{2}$ E repete: "Eis que chegam Eles...". Uma luz azulada desenha um corredor pela escada da plateia. A voz insiste: "Eis que chegam Eles... Eis que chegam Eles...". Então aparece no topo dos degraus um dançarino, com batom vermelho, cílios postiços coloridos, careca e barba grisalha. "Eis que chegam Eles... Os únicos, ímpares!" Ao redor do pescoço, um colar elizabetano de proteção para cachorros e gatos. Veste uma blusa de pelúcia roxa, cobrindo os braços, deixando o peitoral peludo à vista. Usa uma tanga fio dental preta. Pernas de pelo de bode, medindo um metro, alongam seu corpo pequeno.

Eis que chegam Eles... Os únicos, ímpares, inigualáveis, incomparáveis, inimitáveis, singulares, notáveis, indizíveis, inconcebíveis, sui generis, inacreditáveis, incríveis, destacáveis, brilhantes, inimagináveis, extraordinários, insólitos, inusuais, inomináveis, desejáveis, inábeis, supranumeráveis, surreais...

Enquanto isso, o dançarino exibe-se para um público atento à curva em "S" de sua coluna, provocada pela acentuada escoliose.

Em suma, "excepcionais... especiaisss...".

Ao longo de sua performance, ocupa o palco fazendo um striptease das pernasespartilho de bicho, que cobrem seus membros inferiores atrofiados em decorrência da

\footnotetext{
${ }^{2}$ Texto escrito e gravado por Estela Lapponi para nossa performance Nus e [des]graçados, apresentada pela primeira em 2017, no SESC Pompéia, em São Paulo e também utilizado na performance "StripteaseBicho".
} 
poliomielite que adquiriu na infância. Insinua-se em movimentos ondulatórios e repetitivos. Aproxima-se. Afasta-se. Apoia-se sobre as duas mãos, elevando os quadris. Escorrega pelo chão. Rola pelo espaço.

"Eles chegam junto e se manifestam, e vocês poderão até comê-los... se assim eles quiserem!!!".

Inicio este artigo desnudando, aos poucos, o meu corpo, ao descrever parte da performance "Striptease-Bicho", no intuito de gerar imagens que provoquem deslocamentos sobre a Dança e sobre os corpos considerados aptos ou não para dançar, mesmo sabendo que essa compreensão, para o senso comum, ainda está atrelada a certos estereótipos que perseguem este campo das artes.

Ao revelar, paulatinamente, se tratar de uma performance apresentada por um artista com deficiência, quero questionar: Que imagens surgem quando falo em Dança? Que corpo de dançarino lhe aparece? Qual o corpo que dança? No primeiro momento Ihe ocorreu o corpo de um dançarino com deficiência? Que pessoas você imagina aptas a dançar?

Este texto visa borrar padrões, trazer a sinuosidade das colunas em " $\mathrm{S}$ ", propor uma escrita torta, uma dança enviesada da leitura para ressignificarmos nosso olhar condicionado pelo pensamento hegemônico que padroniza, encaixota e determina o ser/estar no mundo.

Sabemos que não é comum pensar no corpo com deficiência como um corpo dançante, assim como pouco se imagina esses corpos/pessoas em outros contextos que não sejam da falta, da doença, da incapacidade, do feio. Considero esse pensamento construído pelo que chamo de "bipedia compulsória" 3 .

\section{"Bipedia compulsória"}

A fim de desenvolver, no doutorado, o conceito "bipedia compulsória", iniciei aproximações com os estudos da Teoria Crip, que, segundo Gavério (2017, p. 55) é:

\footnotetext{
${ }^{3}$ Conceito em desenvolvimento, defendido pelo autor em sua pesquisa no Doutorado Multiinstitucional e Multidisciplinar em Difusão do Conhecimento, por enquanto, intitulada "Atração por um corpo perturbador: bipedia compulsória e seus mecanismos de poder, desejo e repulsa pela deficiência na Dança", sob orientação da Prof ${ }^{a}$ Dr $^{\text {a }}$ Suely Messeder.
} 
(...) uma difusa conexão de 'saberes de fronteira' (ANZALDUA, 1981; 1987; McRUER, 2006) - principalmente no que toca às intersecções entre raça, gênero, sexualidade e deficiência e tem possibilitado pensar duplamente uma crítica das 'políticas identitárias deficientes' emergentes nos anos 1960 e novas e improváveis formas de problematizar a natureza da 'deficiência' e sua contrapartida normalizada e naturalizada, a capacidade (ability).

Atualizando os debates sobre o assunto, a Teoria Crip contesta a compreensão de deficiência defendida pelo modelo social, que por sua vez, já contrastava com o modelo médico.

Para melhor compreensão, a respeito desses modelos que determinam conceitos sobre a deficiência, entende-se que enquanto o modelo médico trata a deficiência pelas questões físicas e biológicas, como uma tragédia pessoal, impondo um olhar sobre o indivíduo, o modelo social, desenvolvido no território dos Disability Studies, refuta a ideia da deficiência como um problema individual e compreende que a sociedade tem responsabilidade pelas desvantagens impostas com as barreiras arquitetônicas, atitudinais, metodológicas, urbanísticas, comunicacionais e tecnológicas.

O estadunidense Robert McRuer (2006), um dos principais nomes da Teoria Crip, aponta que, ainda assim, o modelo social continua reforçando um olhar para o corpo lesionado, distinguindo-o da deficiência que seria causada por questões sociais, e, assim, faz esquecer da construção histórica e cultural desse corpo e de como o corpo com deficiência vem sendo modelado ao longo do tempo.

Ramirez (2019, p. 19)4 entende que, pela lógica do modelo social, “uma pessoa que usa uma cadeira de rodas "não seria 'deficiente'" se todos os lugares tivessem rampas, mas esse modelo tende a esquecer a dimensão cultural do corpo, reduzindo todos os seus esforços ao condicionamento arquitetônico".

O argumento da Teoria Crip tem sido de grande valor para o que venho propondo como "bipedia compulsória", compreendida não como forma de locomoção sobre dois membros, mas sendo uma estrutura social, política, econômica e cultural que determina padrões excludentes pautados na normatividade do corpo, que subjugam e inferiorizam as potencialidades da pessoa com deficiência, tomadas por incapazes e inaptas.

\footnotetext{
${ }^{4}$ Tradução minha.
} 
É uma lógica de organização social que parte da perspectiva de quem não possui deficiência e reconhece o mundo exclusivamente pautado por suas demandas, desconsiderando todos aqueles que estão fora dessa normatividade de corpo. A bipedia que organiza o mundo a partir do seu ponto de vista, exclui e invisibiliza qualquer outra experiência. Bipedia que nega direitos conquistados, silencia nossas falas, nos aprisiona em espaços restritos, nos roubando a liberdade de transitarmos por onde desejarmos.

A bipedia estabelece relações de submissão, reserva apenas vagas de subempregos destinados às cotas para pessoas com deficiência, mesmo que essa tenha formação e qualificação para cargos melhores. Ou, ainda, mantém tratamento infantilizado com as pessoas com deficiência. Ou, quando ocupa os espaços prioritários reservados para esse público, nos estacionamentos ou em frente às rampas de acesso. Ou, quando impede o acesso de um cadeirante a uma sala de exposição porque considera que a cadeira de rodas pode causar acidente e quebrar uma das peças. Ou, quando aborda uma pessoa com deficiência, desejando sua cura e impondo sua fé. Ou, quando se refere à pessoa como "coitadinha". Ou, quando uma professora de Dança, por ignorância, se recusa a dar aula a uma estudante cega por considerar que esta sairá "se batendo" nas outras pessoas 5 . Ou, ou, ou... São muitas situações de preconceito, subalternidade e exclusão onde a bipedia grita e se impõe.

Diante do contato da minha pesquisa com a Teoria Crip e com os escritos de Robert McRouer, identifiquei similaridades entre o que venho desenvolvendo como "bipedia compulsória" e o seu conceito de compulsory ablebodiedness6.

Compreendo a bipedia como compulsória porque entendemos como verdade absoluta o mundo a partir de uma normalidade de corpo. Na relação com a deficiência, desde que nascemos (ou até antes disso) nos é imposta a relação com a bipedia, onde a deficiência é o anormal, o erro, a falta, o que precisa ser corrigido e curado, impondo

\begin{abstract}
a normalidade como o único modelo válido a tornar-se inteligível, portanto, uma ficção corporal que estabelece uma funcionalidade/capacidade nos sujeitos. Entretanto, aqueles que não cumprirem este regulamento estarão localizados em um estado permanente ou momentâneo de dependência e deficiência que necessitará de outro para se tornar viável (RAMIREZ, 2019, p. 11)7.
\end{abstract}

\footnotetext{
${ }^{5}$ Algumas situações vividas pelo autor ou por pessoas conhecidas.

${ }^{6}$ Conceito definido por Robert McRuer, traduzido para o português por Anahi de Mello como

"corponormatividade compulsória", em sua dissertação de mestrado (2014).

7 Tradução minha.
} 
Assim como McRuer (2006), também compreendo a noção de compulsoriedade a partir dos estudos de gênero, que colaboram com o entendimento da heterossexualidade compulsória. Para este autor,

apesar do fato de que a homossexualidade e a deficiência compartilham claramente um passado patologizado e apesar de uma crescente conscientização da interseção entre a Teoria Queer e os Disability Studies, pouco se notou sobre a conexão entre heterossexualidade e identidade corporal. O corpo capaz, ainda mais que a heterossexualidade, ainda se disfarça amplamente como não-identidade, como ordem natural das coisas (2006, p. 1)8.

Gavério (2017, p. 55) destaca ainda que

No Livro Crip Theory: Cultural Signs Of Queerness And Disability (2006), argumenta McRuer que, assim como a heterossexualidade é compulsória em sua lógica que se dissemina a partir da contenção da existência homossexual como uma 'anormalidade', um 'desvio' - a compulsão social pelo 'corpo não deficiente' (able body) se dá pela contenção de existências deficientes, também consideradas anormais e desviantes.

Essa compulsão pelo corpo considerado normal, capaz, apto, está vinculada ao capacitismo que, para Mello (2014, p. 54-55), são "atitudes preconceituosas que hierarquizam sujeitos em função da adequação de seus corpos a um ideal de beleza e capacidade funcional". Podemos pensar que o capacitismo está para as pessoas com deficiência assim como o racismo para as pessoas negras.

Ao mesmo tempo em que se fortalecem os discursos de igualdade de direitos, percebese a perversa compaixão que se estabelece no contato com a pessoa com deficiência, o que promove uma inclusão pela exclusão na manutenção dos estereótipos que nos acompanham e reforçam paradoxos como superação versus coitadinho, autonomia versus falta de acessibilidade, visibilidade versus invisibilidade, herói versus incapaz.

Assim, de acordo com alguns interesses políticos, econômicos e sociais, às pessoas com deficiência são reservados os espaços inclusivos, produzindo discursos de aceitação, valorização dos esforços, a capacidade e superação de alguns indivíduos, promove-se slogans de "super-humanos" como nas Paralimpíadas de Londres, em 2012, e os mantém afastados do meio social, provocando sentimento de dever cumprido e alteridade na bipedia.

Nós, pessoas com deficiência, vivemos, ainda hoje, o período da "vida sem valor"

\footnotetext{
${ }^{8}$ Tradução minha.
} 
(AGAMBEN, 2010), não mais com a morte física, como os antigos faziam ao nos jogar dos despenhadeiros, mas com uma morte social, com a invisibilidade, silenciamento, com os direitos garantidos perante as leis, mas sem o direito de fato de exercê-los, de desfrutá-los.

Estamos no jogo social como o famoso "café com leite" nas brincadeiras infantis. Aquele que está como se não estivesse. Abre-se uma exceção para que possamos participar do jogo, mas sem possibilidade de ganhá-lo porque não estamos jogando de fato. Agamben compreende a relação de exceção como a "forma extrema da relação que inclui alguma coisa unicamente através da sua exclusão" (2010, p. 25).

A bipedia, assim como a branquitude e a heterossexualidade, nas relações étnicoraciais e da sexualidade, respectivamente, pautam toda a construção de mundo, e tudo que não se relaciona com isso está submetido às regras da exceção.

Então, a pessoa com deficiência, a negra, trans, gay ou lésbica, por exemplo, é sempre considerada como "assunto", um fenômeno a ser observado, estudado, compreendido, justamente porque não é considerado dentro da estrutura.

No entanto, compreendo que há um corpo que determina esse pensamento e toda estrutura social. Parece possível afirmar que esse é o corpo bípede, branco, hétero e cis que até hoje ocupa os principais espaços de poder e saber.

Tomando o universo das artes para exemplificar algumas situações, quando se realiza um evento cultural, festivais, simpósios, que não sejam específicos para determinados grupos (deficientes, negros, gays, trans...), há sempre as mesas temáticas para abordarem questões referentes a esses corpos.

Se há uma convocatória para festivais ou editais, com um determinado número de trabalhos a serem selecionados, qual o corpo que determina o critério de seleção? Qual o corpo pauta a curadoria? Quantas pessoas desses grupos citados anteriormente podem ser aprovadas?

As pessoas com deficiência, negras, trans e gays são pensadas como rótulos, marcas, discursos particulares, fechadas em nichos, capazes de falar apenas sobre um tema, limitadas a um único discurso, porque, caso o evento abarque mais pessoas "fora da norma", pode tornarse um evento "temático", e por isso são categorizados e escolhidos "os melhores" entre cada uma dessas categorias, criando disputas entre os próprios pares. Uma briga entre nós mesmos pela mesma fatia da pizza, pelas migalhas do pão.

Porém, defendo que o corpo bípede, branco, hétero e cis, que jamais é categorizado, nem transformado em "assunto", nem rotulado, deve também ser compreendido como um tema, como categoria que carrega discurso, principalmente porque é ele que pauta o principal discurso do pensamento hegemônico. 
Agamben afirma que "não é a exceção que se subtrai à regra, mas a regra que, suspendendo-se, dá lugar à exceção e somente deste modo se constitui como regra, mantendose em relação com aquela" (2010, p. 25).

Então, esse corpo colocado como regra, ao suspender-se e criar privilégios para si, torna-se o princípio, a referência para todas as escolhas, decisões e seleções, estabelecendo um distanciamento ao olhar para os outros corpos, vistos exatamente como "os outros". Por isso mesmo, é aquele que age como se abrisse uma concessão para nossa presença nos espaços.

\section{O fetiche pela deficiência na dança}

Na Dança, que é meu campo de atuação, percebo também a soberania do pensamento bípede. Embora seu conceito tenha se expandido, principalmente em decorrência de algumas vertentes da Dança Contemporânea, ainda é possível observar um pensamento excludente em relação aos corpos com deficiência, que continuam sendo considerados corpos incapacitados para dançar.

É possível perceber um pensamento capacitista e bípede em relação à presença das pessoas com deficiência na Dança, como se o que artistas com deficiência produzem fosse de menos valor. Esse pensamento ainda é muito recorrente nos espaços da Dança, desde espaços de formação até a produção e criação artística. Algumas pessoas continuam a afirmar que a dança não é lugar para corpos com deficiência, se não for no contexto terapêutico ou de reabilitação.

Embora o campo da Dança ainda esteja pautado pela lógica bípede, já consigo identificar fissuras em trabalhos de alguns artistas com deficiência e no meu próprio - é uma tarefa que me proponho também como ação política.

Rancière (2009, p. 36) compreende que "o artista é aquele que viaja nos labirintos ou nos subsolos do mundo social. Ele recolhe os vestígios e transcreve os hieróglifos pintados na configuração mesma das coisas obscuras ou triviais. Devolve aos detalhes insignificantes da prosa do mundo sua dupla potência poética e significante". Para este autor, a arte é política não apenas pelo que se fala, mas pelo próprio fazer artístico, pelas conexões que se estabelecem entre o espaço cênico e a própria superfície da obra.

Para Christine Greiner (2009), em respeito à presença política da Dança, é necessário compreender os nexos, os sentidos, os pensamentos do corpo que dança a partir dos processos que alimentam e modificam suas ações no mundo. Logo, a dança e o corpo que dança não 
estão afastados do ambiente nem do convívio comum quando criam suas danças, mas estão imbricados e respondendo de forma crítica e também emocional, perceptiva, sensorial e cinética aos acontecimentos reais que são experimentados no contexto cênico.

Porém, no que concerne às pessoas com deficiência, penso que continuamos ligados aos estigmas de um corpo sem história, sem desejos, sem sujeito. Um corpo sem pessoa, possível apenas quando se objetifica o indivíduo a partir das categorias que lhe determinam.

Em contrapartida, Auslander e Sandhal (2005, p. 3) acreditam que "manipular e transformar estereótipos são táticas importantes, já que os scripts disponíveis de deficiência tanto na vida diária quanto na representação cultural - são frustrantemente limitados e profundamente enraizados no imaginário cultural".

Dessa maneira, é pelo viés de um corpo poético que na performance "StripeteaseBicho" busco ressignificar olhares sobre o corpo com deficiência na Dança, mas também historicamente renegado no campo da sexualidade e dos prazeres, excluído dos padrões de beleza e considerado repulsivo para os desejos.

Nesse trabalho, proponho uma atitude afirmativa do que sou/somos, explorando radicalmente os movimentos que minha coluna, minha perna fina, flexível, meu desequilíbrio, transformam em dança. Procuro fazer com que o corpo torto de um dançarino não seja submetido às torturantes tentativas de aproximação com as linhas de um corpo bípede, tão valorizadas em determinadas técnicas de Dança, mas que sua tortuosidade seja em si o próprio movimento de uma Dança que segue fluxos errantes e atualizações constantes.

Esse projeto é o desdobramento de uma pesquisa iniciada em 2008 sobre o devoteísmo - fetiche pela deficiência - que culminou no espetáculo "O Corpo Perturbador", criado em 2010, suscitando diversas questões como: O que te perturba? O que é um corpo perturbador? Por que um corpo com deficiência perturba? O que há neste corpo que te atinge, afeta, revela? O que neste corpo te envergonha?

Esse trabalho problematizava o desejo em um mundo que vive sob a égide de um padrão estético rígido - que encontra na mídia seu grande construtor e mantenedor -, mas que, mesmo em pouca medida, ainda consegue ter seus dissidentes.

Nesse caso, pessoas sem deficiência que possuem atração erótica e sexual direcionada às pessoas com deficiência (GAVÉRIO, 2017), ou mais especificamente, à própria deficiência são motivo para muitas controvérsias entre as pessoas com deficiência, pois algumas consideram que o comportamento devotee objetifica seus corpos, sem considerar o sujeito, a pessoa.

Para mim, ao contrário, quando tive o primeiro contato com o assunto, foi um momento revelador. Nesse período, eu, com mais de 30 anos, descobri que meu corpo 
escoliótico e deficiente poderia ser objeto de desejo para um certo grupo de pessoas. Aquilo que durante toda a vida eu compreendi como feio, aberração, indesejável, as partes do meu corpo que por muito tempo eu tentava esconder, camuflar, negar, recolher, eram exatamente o que Ihes estimulavam sexualmente. Minha perna fina, meu corpo torto, atrofiado, meus pés pequenos e lisos... Alguns se interessam pelo coto do amputado, pelo andar e pela muleta de alguém, se excita com uma cadeira de rodas...

Fui compreendendo, tardiamente e mesmo que intuitivamente, pois ao longo da minha formação e construção de sujeito desejante/desejável essa informação nunca havia me chegado, que a sexualidade é mais complexa e que os desejos não seguem padrões rígidos.

Naquela época, iniciei a pesquisa artística acessando o pouco material em português disponível na internet e em contato com os próprios devotees, em salas de bate-papo da UOL voltadas para o público com deficiência. Através desses contatos, fui também descobrindo pontos da minha sexualidade e do corpo que estavam adormecidos. Comecei a ter outra relação com meu próprio corpo e sexo, que reverberou em outros setores da minha vida e como eu passei a olhar para os outros corpos.

Segundo Meinerz (2008, p. 124), a sexualidade no corpo com deficiência se apresenta como um desafio às clássicas teorias do construtivismo social na medida em que suscita discussões em torno da relativização do corpo e das potencialidades físicas e psíquicas relacionadas ao exercício da sexualidade. Certo desconforto do paradigma construtivista devese ao privilégio da realização de análises que privilegiam a dimensão histórica, contextual e simbólica da sexualidade, em detrimento das questões mais próximas à corporalidade (VANCE; ADRESS, 1989).

Ainda, de acordo com Meinerz (op. cit.):

no que tange a interface com a sexualidade, a aplicação [do modelo social] implica a tese de que não são os elementos físicos e psicológicos imediatamente decorrentes das condições corporais diferenciadas que desabilitam as pessoas em relação ao exercício da sexualidade e sim os padrões de normalidade sexual que não comportam às experiências das pessoas desabilitadas. Dito de outro modo, o que desabilita para o sexo para além da incapacidade corporal e cognitiva dos indivíduos são as normas sociais que determinam o que é sexualmente possível e aceitável. A problematização dos aspectos sociais que desabilitam os indivíduos em relação ao exercício da sexualidade contempla as dificuldades estruturais que ultrapassam as peculiaridades de cada tipo de desabilidade.

Na medida em que os aspectos sociais desabilitadores em relação à sexualidade são destacados, com eles emerge a mudança de uma prática discursiva alicerçada na promoção da saúde para outro tipo de discurso cuja ênfase está no direito, no reconhecimento da cidadania 
e na busca de uma não-patologização, da variação e da diversidade corporal e sexual.

Trazendo para o campo da Dança, esta mesma problematização ainda se faz presente quando um corpo com deficiência não é o padrão de normalidade.

É importante trazer a perspectiva do corpo como contexto/conteúdo (LLINÁS, 2003; KATZ, 2005), que é contaminado por sua própria ação. Assim sendo, dançar é contaminar. Contaminar pelo fato de fazer relações, interpretações que provocam deslocamentos e novos entendimentos. O corpo dançarino e sua dança estão embebidos um pelo outro. Tudo aquilo que se mostra responde às condições de possibilidade do campo de ação desse corpo, às práticas em que está imerso.

Para a coreógrafa, dançarina e pesquisadora em Dança, Fafá Daltro9

\begin{abstract}
O Corpo Perturbador é uma obra que, além de alavancar discussões sobre o corpo, deficiência e acessibilidades, nos fazem refletir sobre os discursos equivocados a respeito dessas pessoas como incapazes de construir conhecimentos. Esta obra nega cabalmente tal proposição. Efetivamente, as lacunas que insistem em residir no campo da dança sobre o assunto ainda encontram dificuldades para elucidar e franquear o acesso desses artistas que apontam novos modos de organizações de corpo inovadores que causam certos estranhamentos percepcionais, ou seja, um preconceito generalizado e difundido no mundo da dança e no imaginário social, justo por não encontrarem nesses ambientes de direito, espaços de representatividade e de convívio comum. Por suas próprias ausências tão comuns no ambiente artístico suas aparições soam e reverberam esses estranhamentos ao revelar seus corpos escolióticos e deformados pela paraplegia desvestidos. Expostos estão suas curvas e questionamentos que se debatem e embatem rastejando por entre as pernas das cadeiras $\mathrm{e}$ as pernas das pessoas. Por que se esgueiram? O que nos questionam? $\mathrm{O}$ seu plano de visibilidade é outro, é o solo, o chão, exige que desviemos o olhar para o que se apresenta esparramado no chão prolongados pelos corpos bichos estendidos, agora transformados em lugar de significados.
\end{abstract}

A pesquisa artística do espetáculo "O Corpo Perturbador" me fez ainda ampliar o espectro de suas discussões, pois me fez perceber certos aspectos do devoteísmo que associei a determinados comportamentos recorrentes nas relações sociais, políticas, culturais e religiosas estabelecidas com as pessoas com deficiência e também na Dança.

O que, a princípio, se mostrou revelador e transformador da minha relação com meu próprio corpo, foi apresentando, de maneira geral, determinadas camadas que revelavam mecanismos de poder para manutenção da hierarquia do corpo bípede sobre o corpo com

\footnotetext{
${ }^{9}$ Relato de Fafá Daltro transcrito em meu blog homônimo ao espetáculo "O Corpo Perturbador". Disponível em: <https://ocorpoperturbador.blogspot.com/search?q=fafa+daltro $>$. Acesso em: 15 out 2019.
} 
deficiência.

Dessa maneira, comecei a compreender o fetiche para além de um desejo/pulsão/estimulo sexual, mas perpassando diversos aspectos da deficiência, inclusive nos processos de criação e produção artística.

Venho observando, ao longo dos meus estudos, comportamentos fetichistas no caso das produções de grupos que trabalham com pessoas com e sem deficiência. Normalmente, os projetos iniciam pelo desejo da pessoa não-deficiente em trabalhar com esse público, lançando um olhar exclusivamente na deficiência (assim como os devotees) e de como essa relação determina os comportamentos e espaços de atuação dos envolvidos.

Em grande parte dos projetos, as pessoas com deficiência são convidadas a participarem simplesmente pela sua condição física. Eu mesmo comecei a dançar em um grupo por causa da minha deficiência, não porque soubessem que eu tinha alguma aptidão para dançar. Isso não chega a ser um critério para que pessoas com deficiência ocupem esses espaços.

Em minha pesquisa de mestrado (CARMO, C. E. O., 2014, p. 84)10, em entrevista, a artista e pesquisadora Carolina Teixeira lembra que,

\begin{abstract}
normalmente, esses trabalhos são constituídos por um corpo profilático, assistencial e de suporte formado por uma equipe multidisciplinar, integradas por, além do professor de dança, médicos, assistentes sociais, fisioterapeutas, psicólogos, pedagogos e arte-educadores. O que, de alguma forma, compromete a qualidade estética e artística dos trabalhos, pois estes ficam submetidos aos interesses e à visão institucional que ditam as regras e ignoram os processos de construção do corpo-artista, pois não tem conhecimentos específicos sobre o assunto.
\end{abstract}

Fica evidente, nesses casos, a hierarquização nas relações entre as pessoas com e sem deficiência, onde raramente a pessoa com deficiência assume uma postura autônoma, propositora, criativa. O que acontece também na maioria das companhias de dança, geralmente, dirigidas, coreografadas e produzidas por pessoas sem deficiência.

Embora o trabalho seja desenvolvido com pessoas com deficiência, as possibilidades estéticas e poéticas da deficiência não são levadas em consideração, sequer são pensadas como possibilidades. O que se percebe, são propostas artísticas que tentam reproduzir os cânones da

\footnotetext{
${ }^{10}$ Pesquisa desenvolvida no Programa de Pós-Graduação em Dança (PPGDANCA), no período de 2012 a 2014, com o título "Entre sorrisos, lágrimas e compaixões: implicações das políticas culturais brasileiras (2007 a 2012), na produção de artistas com deficiência na dança", sob orientação da Prof ${ }^{\mathrm{a}}$ Dr $^{\mathrm{a}}$ Lúcia Matos.
} 
normalidade construídos historicamente em relação ao corpo, apresentando o pensamento comum de uma dança ideal, virtuosa - uma dança bípede.

Os profissionais envolvidos, tanto os professores, fisioterapeutas ou educadores físicos sabem que a dança alcança resultados fortuitos no que diz respeito à reorganização do corpo nos diversos níveis: cognitivo, motor, psíquico. Nos seus projetos utilizam a arte como meio de satisfazer a essas demandas e não se prioriza o pensamento artístico, principalmente porque não é esse o contexto.

Além disso, esses profissionais demonstram um conhecimento parcial da dança enquanto área de conhecimento, por isso mesmo potencializam o discurso apoiado em uma estética de um corpo padrão, das formas, linhas e movimentos de uma dança que não corresponde às potencialidades do corpo com deficiência.

Tenho questionando, nos últimos anos, certos procedimentos que acolhem a diversidade corporal na Dança. Inclusive, alguns meios da Dança Contemporânea, que é compreendida como um espaço para diversos corpos, códigos, metodologias e práticas, mostram-se bastante reticentes no acolhimento, de fato, dessas corporalidades dissidentes, ou seja, aquelas que não correspondem a certo padrão já estabelecido.

Recentemente, participei de um evento internacional onde o coreógrafo de um grupo com jovens com deficiência intelectual postou-se na frente do palco e comandava os movimentos de dois adolescentes como se adestrasse animais. Gritava fora da cena: "senta", "levanta", "gira"... Obviamente, ali estava a bipedia impondo estruturas rígidas para composição e criação em Dança, desrespeitando a temporalidade e as possibilidades de colaboração daqueles sujeitos na construção do espetáculo. Firma-se, previamente, o que seria Dança e como criá-la, sem a aproximação e diálogo reais com aquelas pessoas implicadas no processo.

Por outro lado, observa-se um grande equívoco no comportamento de alguns artistas com deficiência ao submeterem-se às exigências estéticas do padrão estabelecido para a Dança, buscando corresponder às linhas fixas de algumas técnicas, dos movimentos considerados belos e limpos, do estímulo à comoção do público, acreditando que, dessa forma, podem alcançar maior visibilidade ou penetração na mídia e nos meios da Dança.

No fundo, por mais que busquem essa aproximação, ainda estarão representando a antítese do que o pensamento hegemônico dita como verdade, pois o corpo com deficiência não poderá jamais corresponder fielmente a esse padrão. Como a deficiência é uma marca (biológica, social e cultural) que caracteriza esse indivíduo, essa nunca poderá ser ignorada ou deixará de existir. 
Defendo que a "bipedia compulsória" opera pela lógica do pensamento abissal (SANTOS, 2010, p. 20) que divide "as experiências, os saberes e os atores sociais entre os que são úteis, inteligíveis e visíveis (os que ficam do lado de cá da linha) e os que são inúteis ou perigosos, ininteligíveis, objetos de supressão ou esquecimento", os "do lado de lá da linha".

Na Dança, também as linhas abissais se fazem presente, estabelecendo fronteiras de manutenção do poder e do saber entre "este lado da linha", formado pelo corpo bípede, e "o outro lado da linha", ocupado pelo corpo com deficiência, referenciado sempre como "o outro corpo na dança", os especiais, diferentes, guardados na caixinha da diversidade.

Para Santos (2010), o outro lado da linha compreende uma grande variedade de experiências desperdiçadas, tornadas invisíveis e, assim como seus autores, sem a possibilidade de emersão de suas singularidades.

Infelizmente, nesse sentido, em comparação ao contingente da Dança, no Brasil, ainda observo um número muito reduzido de artistas com deficiência que tem conseguido furar o bloqueio da "bipedia compulsória", ocupando determinados espaços, anteriormente inacessíveis. No entanto, existem brechas por onde alguns sujeitos "fora da regra" conseguem passar e começam a subverter determinadas lógicas e apontar para outras possíveis perspectivas.

Eles existem e destacam-se justamente por não reproduzirem os cânones de uma Dança que não corresponde à sua corporalidade e apresentam novas possibilidades corporais, estéticas, poéticas e políticas para a construção de conhecimento na área e consequentemente influenciam outros campos de saber.

Por fim, surgem inúmeras questões que me instigam a pensar de que maneira podemos produzir mudanças paradigmáticas na relação bípede com as pessoas com deficiência, compreendendo a própria deficiência, na Dança, como uma escolha estética, política, produtora de poéticas e sentidos.

\section{Referências}

AGAMBEN, Giorgio. Homo Sacer: o poder soberano e a vida nua I. 2. ed. - Belo Horizonte: Editora UFMG, 2010.

AUSLANDER, Phillipe; SANDHAL, Carrie. Bodies in commotion: disability and performance. Michigan: Michigan Press, 2005.

CARMO, C. E. O. Entre sorrisos, lágrimas e compaixões: implicações das políticas culturais brasileiras (2007 a 2012), na produção de artistas com deficiência na dança. 2014. Dissertação - (Mestrado em Dança), Escola de Dança, Universidade Federal da Bahia, Salvador, 2014. 
CORREIA, Fátima. O Corpo Sitiado. A Impossível Visibilidade. Dança, Rodas e Poéticas. Tese - (Doutorado em Comunicação e Semiótica) - Escola de Dança da UFBA e Pontifícia Universidade Católica de São Paulo, 2007.

GAVÉRIO, Marco Antonio. Estranha Atração: Criação de Categorias Científicas para Explicar os Desejos pela Deficiência. Dissertação - (Mestrado em Sociologia) Programa de Pós-Graduação em Sociologia, Universidade Federal de São Carlos, São Carlos, 2017.

GREINER, Christine. La visibilidad de la presencia del cuerpo como estrategia política. In: Bultagro, Ana (Org.). Arquiteturas de la mirada. Universidade de Alcatá, 2009.

McRUER, Robert. Crip Theory: Cultural Signs of Queerness and Disability. New York: New York University Press, 2006.

MELLO, Anahi Guedes de. Gênero, Deficiência, Cuidado e Capacitismo: uma análise antropológica de experiências, narrativas e observações sobre violências contra mulheres com deficiência. Dissertação (Mestrado em Antropologia Social) Programa de Pós-Graduação em Antropologia Social, Universidade Federal de Santa Catarina, Florianópolis, 2014.

MEINERZ, N. E. Corpo e Outras (De) Limitações Sexuais. Uma Análise Antropológica das publicações da Revista Sexuality and Disability entre os anos de 1997 e 2006. Revista Brasileira de Ciências Sociais, vol. 25, n. 72 , p. $117-178,2010$

RANCIÈRE, Jacques. Política da Arte. Transcrição do seminário "São Paulo S.A, práticas estéticas, sociais e políticas em debate". São Paulo: SESC Belenzinho, 17 a 19 de abril de 2005. Disponível em: <http://www.sescsp. org.br/sesc/images/upload/ conferencias/206.rtf> Acesso em: 10 de out 2019.

SANTOS, Boaventura de Sousa. Para além do pensamento abissal: das linhas globais a uma ecologia de saberes. In: SANTOS, Boaventura de Sousa; MENESES, Maria Paula (Org.). Epistemologias do Sul. São Paulo: Cortez, 2010. p. 31-83.

VANCE, C. S.; ADDRESS. Social Construcionism Theory: Problems in the history of Sexuality. In: ALTMAN, D. Et al. Which Homosexuality? Essays from the International conference on lesbian and gay studies. London: GMP Publischer, 1989 